\title{
Isolation of Clones of Rat Striatum-Specific mRNAs by Directional Tag PCR Subtraction
}

\author{
Hiroshi Usui, ${ }^{a}$ Jeffrey D. Falk, Ana Dopazo, Luis de Lecea, Mark G. Erlander, and J. Gregor Sutcliffe \\ Department of Molecular Biology, The Scripps Research Institute, La Jolla, California 92037
}

\begin{abstract}
We report an improved subtractive cDNA cloning procedure, named "directional tag PCR subtraction," for isolating clones of mRNAs enriched in a target tissue compared to a second tissue, the driver. In this method, the target and driver are prepared from directional cDNA libraries constructed in different vectors, and the target cDNA contains tag sequences at both its $5^{\prime}$ and $3^{\prime}$ ends for PCR amplification. This method avoids several limitations of previous subtraction procedures, and was demonstrated to be technically easy and efficient. Using the directional tag PCR subtraction and improved screening procedures, cDNA clones corresponding to mRNAs expressed in the striatum but not in the cerebellum of the rat brain were efficiently isolated, including mRNAs encoding calmodulin-dependent phosphodiesterase, a transcriptional regulatory protein, and several previously uncharacterized species. Our data suggest that approximately $1 \%$ of the striatal polyA+ RNA mass potentially encoding more than $\mathbf{3 0 0}$ distinct proteins corresponds to RNA species reduced in concentration or absent from the cerebellum, of which about one-third are expressed prominently only in the striatum. This unexpected finding suggests that the striatum has a unique biochemical character within the brain, and that characterization of these mRNAs will be important for understanding the biochemical basis of striatal function.

IKey words: subtractive CDNA cloning, PCR, striatum, rat brain, gene expression, calmodulin-dependent phosphodiesterase, BTE-binding protein]
\end{abstract}

cDNA cloning is a powerful technique for identifying and isolating mRNA molecules, and is the fundamental step for analysis of the primary structure of their encoded protein and subsequent functional studies. Several approaches have been used to isolate cDNA clones of differentially expressed mRNAs (reviewed by Travis et al., 1989b). These approaches include differential screening (plus-minus screening), screening with a subtracted cDNA probe, and cloning of subtracted cDNA into a vector. However, generally speaking, isolation of clones of differentially expressed mRNAs is a formidable task, especially

\footnotetext{
Received Oct. 11, 1993; revised Jan. 24, 1994; accepted Feb. 16, 1994.

We thank Patria Danielson, Jeffrey Burns, Pamela Foye, and Janine Dowgialo for excellent technical assistance. This work was supported in part by grants from the NIH (NS22347, NS22111, GM32355, HG00332) and the Dystonia Medical Research Foundation.

Correspondence should be addressed to J. Gregor Sutcliffe, Department of Molecular Biology-MB10, The Scripps Research Institute, 10666 North Torrey Pines Road, La Jolla, CA 92037.

a Present address: Department of Neuropathology, Brain Research Institute, Niigata University, Niigata 951 , Japan.

Copyright (c) 1994 Society for Neuroscience 0270-6474/94/144915-12\$05.00/0
}

when the target mRNAs are expressed at low concentrations. Differential screening allows isolation only of clones of relatively abundant (>0.06\%) mRNAs (Dworkin and Dawid, 1980). Screening subtracted cDNA libraries improves the efficiency of the isolation of differentially expressed clones; however, the construction of subtracted cDNA libraries has been difficult, even though several procedures have been reported (considered in detail in the Discussion).

We previously developed a powerful subtractive hybridization procedure that utilized cloned cDNA driver and hybridization in phenol cmulsion (PERT) and allowed ncarly quantitative isolation of clones of mRNAs of both high and low concentrations in the target tissue (Travis and Sutcliffe, 1988). Despite several successful applications of this method (cf. Travis et al., 1989a; Watson et al., 1992), our experience with it has been inconsistent. In different researchers' hands the outcomes have been variable, leading us to search for a more dependable methodology.

Here, we report an improved procedure for subtracted cDNA cloning. In this method, a subtracted cDNA library and subtracted cDNA probe are prepared by PCR from a specially designed cDNA target. We applied this approach effectively to isolate cDNA clones of $m$ RNAs that are expressed in the striatum but not in the cerebellum of the rat brain. Previous reports demonstrate that mRNAs differentially expressed among the brain regions are only rarely encountered (Travis et al., 1987). However, we easily isolated clones of striatum-enriched mRNAs in higher proportion than that previously supposed, using the new subtraction method and improved screening and selection procedures. Because of the conceptual and experimental simplicity of the method, the commercial availability of all of the reagents required for its application, its relatively low consumption of radioactive compounds, the ease with which its step can be monitored, and the unexpectedly large number of experimentally confirmed, differentially expressed mRNAs it has identified, we are enthusiastic about its general utility and portability to other laboratories.

\section{Materials and Methods}

Preparation of RNA. Total RNA was isolated from dissected tissue of adult Sprague-Dawley rats by the acid guanidinium thiocyanate-phenolchloroform extraction method (Chomczynski et al., 1987) or extraction with guanidinium isothiocyanate followed by centrifugation with cesium chloride solutions (Sambrook et al., 1989). PolyA ${ }^{+}$RNAs were purified by oligo(dT) cellulose column chromatography using the standard procedure (Sambrook et al., 1989).

Construction of $c D N A$ libraries. Directional cDNA libraries of striatum and cerebellum mRNAs were constructed for this study as follows. Rat striatum and cerebellum cDNAs were prepared from $2 \mu \mathrm{g}$ of each polyA-enriched RNA using the TimeSaver cDNA Synthesis Kit and 
Directional cloning toolbox (Pharmacia, Piscataway, NJ) according to the manual of the vender. Briefly, double-stranded cDNA was synthesized by the Gubler-Hoffman method using a NotI-oligo(dT) primer, ligated to an EcoRI linker, digested with the restriction enzyme NotI and then cloned into a phagemid vector. The rat striatum directional cDNA library was constructed in pT7T3D 18U NotI/EcoRI/BAP (Pharmacia), and used for preparing the target. The rat cerebellum directional cDNA library was constructed in a second phagemid vector, pGEMI I Zf(-) (Promega, Madison, WI), and used to prepare the driver. The directional cloning vector pGEM11Zf(-) was prepared for cloning by double digestion with NotI and EcoRI restriction endonucleases and dephosphorylation with calf intestine alkaline phosphatase (Boehringer Mannheim, Indianapolis, IN), and was spun through a Sephacryl S-400 column (Pharmacia) to remove the small NotI-EcoRI fragment.

Rat cerebellum and hypothalamus cDNA libraries were constructed in the pT7T3DI8U NotI/EcoRI/BAP by the same method as for the rat striatum cDNA library construction, and used for preparing a cDNA probe for differential screening of the subtracted cDNA library or for cDNA library-Southern blot analysis, as described below.

Each cDNA-vector preparation was transfected into strain MC1061 cells by a high-voltage electroporation method (Dower et al., 1988), and amplified in liquid media under ampicillin selection. Based on the number of ampicillin-resistant colonies before amplification, the number of recombinants in each library was estimated to be approximately $10^{6}$. Random picking of the colonies of each library showed that almost all the clones contain a cDNA insert. Phagemid DNAs from each directional cDNA library were prepared by standard alkaline lysis followed by the purification using equilibrium centrifugation in $\mathrm{CsCl}$-ethidium bromide (Sambrook et al., 1989).

Procedure for directional tag $P C R$ subtraction. Specially designed target cDNA was prepared by the following procedure (outlined in Fig. $1 A$ ). The rat striatum directional cDNA library DNA in the pT7T3D vector was linearized by digestion with NotI. Sense-strand striatum cRNA was synthesized in vitro with T7 RNA polymerase from the digested DNA using an RNA transcription kit (Stratagene, La Jolla, CA). After the template DNA was removed with RNase-free DNase, the RNA product was purified with a Nuctrap push column (Stratagene). Antisense striatum cDNA was then synthesized with M-MLV reverse transcriptase (GIBCO-Bethesda Research Laboratory, Gaithersburg, MD) from $1 \mu \mathrm{g}$ of the cRNA product using the Notl-oligo(dT) primer $\left(5^{\prime}-\mathrm{A}\right.$ ACTGGAAGAATTCGCGGCCGCAGGAATTTTTTTTTTTTTTTTTT-3'; Pharmacia). A trace amount of $\alpha^{-32} \mathrm{P}-\mathrm{dCTP}$ was included in the reaction mixture to allow later quantification of the cDNA target after subtraction. The product was treated with alkali to hydrolyze the RNA template (Sambrook et al., 1989), and the resulting antisense cDNA was used as the target for subtractive hybridization. This striatum cDNA target has tag sequences at both its $5^{\prime}$ and $3^{\prime}$ ends. The $5^{\prime}$ tag sequence corresponds to the Notl-oligo(dT) primer, whereas the $3^{\prime}$ tag sequence corresponds to the polycloning site of the pT7T3D vector. These tag sequences are used for amplification of the target cDNA after the subtraction procedure.

The driver for the subtraction was prepared as follows (Fig. $1 B$ ). The directional cerebellum cDNA library constructed in pGEM $11 \mathrm{Zf}(-)$ was linearized with the restriction enzyme HindIII, and sense-strand cerebellum CRNA was transcribed with T7 RNA polymerase. After the template DNA was removed with RNase-free DNase, the RNA product was purified with a Nuctrap push column and used as driver for subtractive hybridization. The RNA driver has a short tag sequence in the $5^{\prime}$ end that corresponds to the polycloning site of the pGEM11Zf $(-)$ vector, but there is no possibility of cross-hybridization with the tag sequences in the target, because the sequence of the polycloning site in pGEM1IZf $(-)$ is unrelated to that in the pT7T3D vector.

The trace-labeled antisense striatum cDNA target (synthesized from I $\mu \mathrm{g}$ of the striatum sense cRNA) was mixed with $20 \mu \mathrm{g}$ of the sense cerebellum cRNA driver in $10 \mu \mathrm{l}$ of hybridization buffer containing 0.5 $\mathrm{M} \mathrm{NaCl}, 50 \mathrm{~mm}$ HEPES (pH 7.6), 2 mm EDTA, and 0.2\% SDS. The samples were overlaid with $50 \mu \mathrm{l}$ of mineral oil, boiled for $90 \mathrm{sec}$, and then incubated at $68^{\circ} \mathrm{C}$ for $24 \mathrm{hr}$ in $500 \mu \mathrm{l}$ Eppendorf tubes. Under these conditions, $\mathrm{C}_{0} \mathrm{t}$ values (corrected to standard salt conditions) of $>2000$ were obtained (Britten et al., 1974). After the incubation, the sample was extracted with chloroform and phenol, precipitated with ethanol, and dissolved in $500 \mu \mathrm{l}$ of $50 \mathrm{~mm}$ phosphate buffer (PB), pH 6.6, containing $0.2 \%$ SDS. The sample was then loaded onto a jacket column (Bio-Rad, Richmond, CA) maintained at $60^{\circ} \mathrm{C}$ containing $1 \mathrm{ml}$ of hydroxylapatite (DNA grade Bio-Gel HTP, Bio-Rad) that was equilibrated with $50 \mathrm{~mm} \mathrm{~PB} / 0.2 \%$ SDS. After the column was washed with $6 \mathrm{ml}$ of $50 \mathrm{~mm} \mathrm{~PB} / 0.2 \%$ SDS, the single-stranded cDNA was eluted with $6 \mathrm{ml}$ of $120 \mathrm{~mm}$ PB containing $0.2 \% \mathrm{SDS}$, and the cDNA hybridized with the driver RNA was eluted with $6 \mathrm{ml}$ of $400 \mathrm{~mm} \mathrm{~PB} / 0.2 \%$ SDS. The single-stranded target cDNA was concentrated and desalted with Centricon-30, precipitated with ethanol, and incubated again with $20 \mu \mathrm{g}$ of the cerebellum cRNA driver for the second round of the subtraction. The single-stranded target cDNA eluting in $120 \mathrm{~mm}$ PB fraction of the second hydroxylapatite column was passed through Centricon-30, treated with $0.36 \mathrm{M} \mathrm{NaOH}$ for $30 \mathrm{~min}$ at $68^{\circ} \mathrm{C}$ to hydrolyze the RNA driver, precipitated with ethanol, and used as a template of PCR.

The subtracted cDNA target was amplified by PCR using the primers specific to the tag sequences in the target (5'-AACTGGAAGAATTCGCGG-3' and 5'-AGGCCAAGAATTCGGCACGA-3'). The PCR was performed in a $100 \mu \mathrm{l}$ volume in a Perkin-Elmer/Cetus Thermal Cycler, using a buffer containing 6.7 mM Tris- $\mathrm{HCl}, \mathrm{pH} 8.8,16.7$ mM ammonium sulfate, $6.7 \mathrm{~mm} \mathrm{MgCl}_{2}, 5 \%$ dimethyl sulfoxide (DMSO) $0.01 \%$ gelatin, $100 \mu \mathrm{M}$ of each dNTP, $0.8 \mu \mathrm{M}$ of each primer, and $2 \mathrm{U}$ of Taq polymerase (Perkin-Elmer/Cetus, Emeryville, CA). The 30-reaction cycle consisted of denaturation at $94^{\circ} \mathrm{C}$ for $15 \mathrm{sec}$, annealing at $60^{\circ} \mathrm{C}$ for $15 \mathrm{sec}$, and elongation at $72^{\circ} \mathrm{C}$ for $1 \mathrm{~min}$.

To construct the striatum-minus-cerebellum subtracted cDNA library, the amplified cDNA product was digested with NotI and EcoRI (which cleave within the tags), separated from primers and the flanking sequences with a Sephacryl S-300 spin column, and ligated into the pT7T3D EcoRI/NotI/BAP.

Dot blot analysis using the subtracted cDNA probe. The single-stranded striatum cDNA target from the second round of the subtraction was used to prepare a cDNA probe. The subtracted cDNA was labeled by the PCR using the same conditions as described above for the subtracted cDNA library construction, except nucleotide concentration: $100 \mu \mathrm{M}$ of each dGTP, dATP, dTTP, $10 \mu \mathrm{M}$ of dCTP, and $16.7 \mathrm{pmol}$ of $\alpha{ }^{-32} \mathrm{P}$ dCTP ( $3000 \mathrm{Ci} / \mathrm{mmol}$; New England Nuclear). The labeled, amplified cDNA fragments were purified from unincorporated label with a Sephadex G-50 spun column, and then used as a probe for dot blot analysis to examine the effectiveness of the subtraction. Plasmids containing cDNA inserts of RC3, CPul, IG5, NSE (neuron-specific enolase), or cyclophilin (Forss-Petter et al., 1986; Danielson et al., 1988; Watson et al., 1990, 1992; Godbout et al., 1993), or vector with no insert, were spotted in fivefold dilutions on nylon filters and the filters hybridized with the subtracted striatum cDNA probe. As a control, the dot blot filter was hybridized with an unsubtracted striatum cDNA probe, which was amplified and labeled by PCR from the unsubtracted striatum target using the same conditions as those used for preparing the subtracted cDNA probe.

Differential screening of the subtracted cDNA library. An aliquot of the subtracted cDNA library was transfected into competent cells and individual transfectants were picked onto nylon filters from which replicas were prepared. Each filter was hybridized with a cerebellum cDNA probe, an unsubtracted or the subtracted striatum cDNA probes. The subtracted and unsubtracted striatum cDNA probes were prepared by PCR as described above. The cerebellum cDNA probe was prepared by the same method as the striatum cDNA probes from a directional cerebellum cDNA library constructed in the pT7T3D vector. The filters were hybridized with an equal number of radioactive counts for each probe in $50 \%$ formamide at $42^{\circ} \mathrm{C}$, and washed at a final high stringency of $0.2 \times \mathrm{SSC}(1 \times \mathrm{SSC}$ is $0.15 \mathrm{M} \mathrm{NaCl}, 0.015 \mathrm{~m}$ sodium citrate $)$ and $0.2 \%$ SDS at $68^{\circ} \mathrm{C}$

Rapid confirmation of $M R N A$ distribution by $C D N A$ library blot analysis. A cDNA library-Southern blot method was used to analyze the expression patterns of candidate clones selected by the differential screening of the subtracted cDNA library. Amplified DNAs from the rat striatum, cerebellum, and hypothalamus cDNA libraries, each of which was constructed in the pT7T3D vector, were digested with the restriction enzyme HaeIII, separated by electrophoresis on a $1.2 \%$ agarose TBE gel, and transferred to nylon filters. Each filter was hybridized with a cDNA probe prepared from an individual candidate clone. To prepare the probes, miniprep plasmid DNAs were prepared by the boiling method (Sambrook et al., 1989), diluted 1000-fold, and used as a template for a PCR. Each cDNA insert was amplified using primers corresponding to the sequences adjacent to the NotI- and EcoRI-cloning sites of the pT7T3D vector (5'-AGGCCAAGAATTCGGCACGA-3' and $5^{\prime}$-AGGATCCGCGGCCGCAGGAA-3'). The PCR was performed in a volume of $20 \mu \mathrm{l}$ with $100 \mu \mathrm{M}$ of $\mathrm{d}(\mathrm{A}, \mathrm{G}, \mathrm{T}) \mathrm{TP}, 10 \mu \mathrm{M}$ of dCTP, and 3.3-6.6 pmol (1-2 $\mu$ l) of $\alpha{ }^{-32} \mathrm{P}-\mathrm{dCTP}(3000 \mathrm{Ci} / \mathrm{mmol}$; New England 
Notl

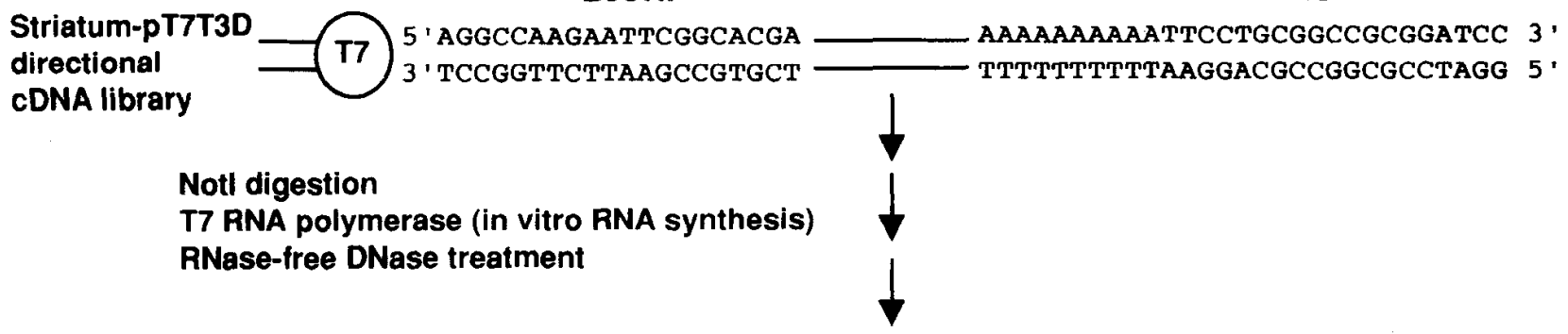

Striatum sense RNA

$$
5 \text { ' AggCCAAGAATTCGgCACGA }
$$

aAAAAAAAAATTCCTGC 3 '

Reverse transcriptase

with Notl-oligo(dT18) primer

and $\left[\alpha{ }^{32} \mathrm{P}\right] \mathrm{dCTP}$ as a tracer

Hydrolysis of RNA

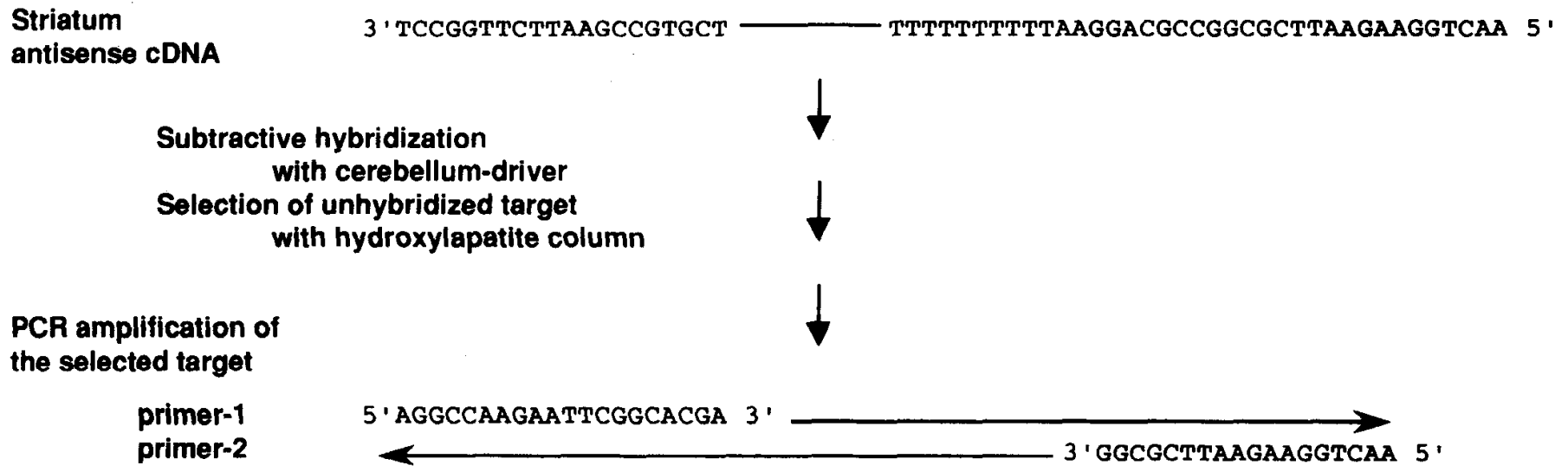

B

Cerebellum-pGEM11zf(-) directional cDNA library

$\downarrow$ Hind III digestion
$\downarrow \quad$ in vitro RNA synthesis with T7 RNA polymerase

Cerebellum sense RNA

$\downarrow$ RNase-free DNase treatment

Hybridization with striatum CDNA target

Figure 1. Schematic representation of the procedure for directional tag PCR subtraction. A, Procedure for target cDNA preparation. B, Procedure for driver RNA preparation. 


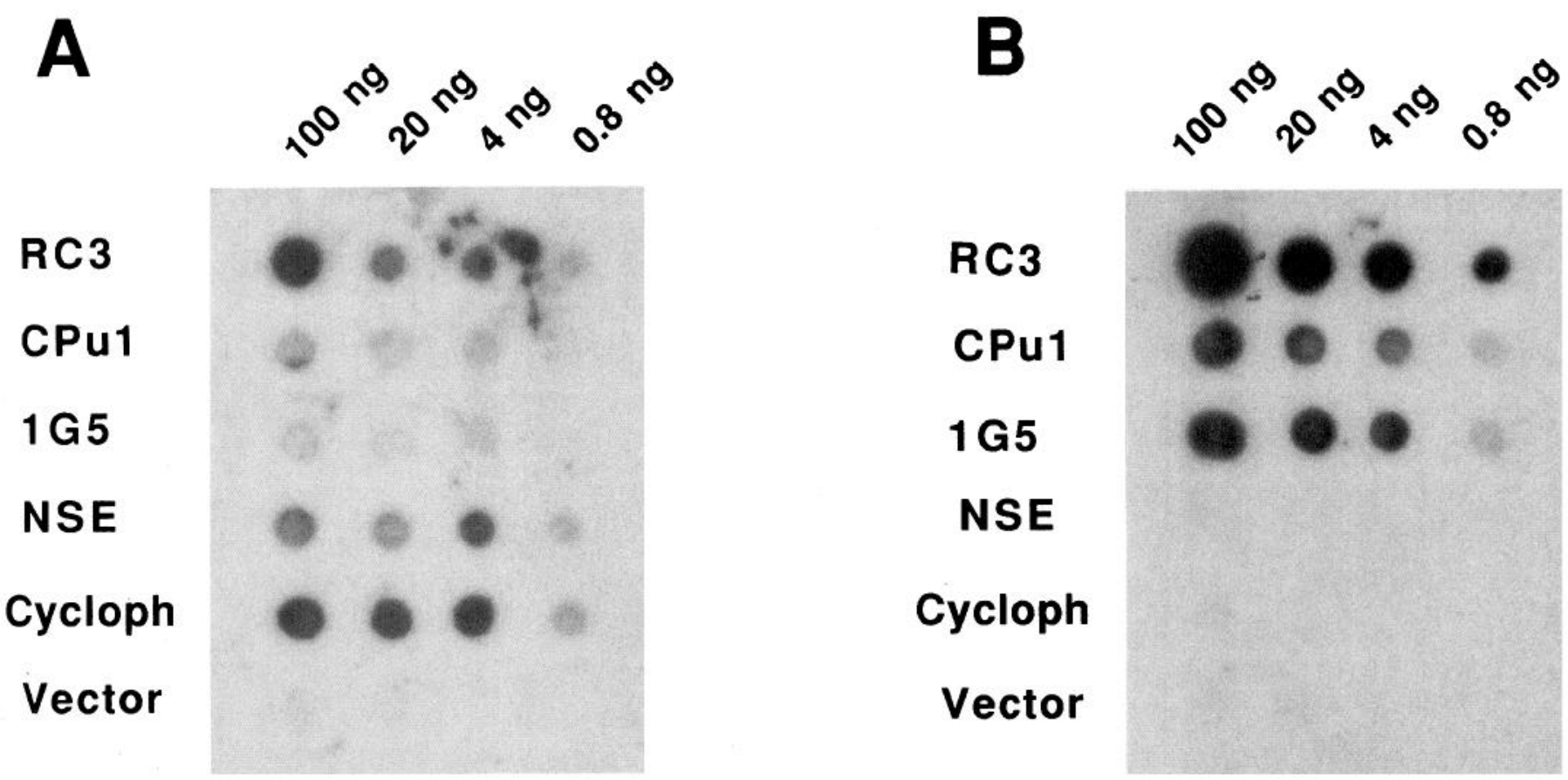

Figure 2. Dot blot analysis to access the effectiveness of the subtraction. The filter on which several plasmid DNAs were spotted in serial fivefold dilutions $(100-0.8 \mathrm{ng})$ was hybridized with the control unsubtracted probe $(A)$ or subtracted cDNA probe $(B)$. The spotted plasmids have a cDNA insert of RC3, CPul, IG5, NSE, or cyclophilin. Plasmid vector without cDNA insert was also spotted as a control.

Nuclear), using 30 cycles of $15 \mathrm{sec}$ at $94^{\circ} \mathrm{C}, 15 \mathrm{sec}$ at $68^{\circ} \mathrm{C}$, and $1 \mathrm{~min}$ at $72^{\circ} \mathrm{C}$. The cDNA probes were purified from unincorporated label with Sephadex G-50 spun columns and used for hybridization. After the hybridization in $50 \%$ formamide at $42^{\circ} \mathrm{C}$, the filters were washed in $0.2 \times \mathrm{SSC}, 0.2 \%$ SDS at $68^{\circ} \mathrm{C}$.

Northern blot analysis. PolyA-selected RNA $(2 \mu \mathrm{g})$ from different rat brain regions and several peripheral tissues were separated by electrophoresis on a $1.5 \%$ agarose gel containing formaldehyde, transferred to nitrocellulose filters, and hybridized with the cDNA probes prepared from candidate clones. The cDNA insert from each candidate clone was labeled with $\alpha{ }^{-32} \mathrm{P}$-dCTP by PCR as described above, and the hybridization was performed in the same condition as described in the differential screening of the subtracted cDNA library.

Nucleotide sequence analysis. Nucleotide sequences were determined by the dideoxy chain termination method with $\alpha{ }^{-35}$ S-dCTP, using the Sequenase 2.0 kit (U.S. Biochemical, Cleveland, $\mathrm{OH}$ ) and primers corresponding to vector sequences flanking the cDNA inserts. The EMBL database was searched with the nucleotide sequences of the striatumenriched cDNA clones using the FASTDB program (Brutlag et al., 1990).

In situ hybridization. In situ hybridization analysis was performed essentially according to the method described previously (Gall and Isackson, 1989; Erlander et al, 1993). Coronal sections, $25 \mu \mathrm{m}$ thick, from adult Sprague-Dawley rats were hybridized at $55^{\circ} \mathrm{C}$ for $16 \mathrm{hr}$ with ${ }^{35} \mathrm{~S}$ labeled single-stranded RNA probes at $10^{7} \mathrm{cpm} / \mathrm{ml}$. Free-floating sections were treated with RNase A at $4 \mu \mathrm{g} / \mathrm{ml}$ at $37^{\circ} \mathrm{C}$ for $1 \mathrm{hr}$, and washed in $1 \times \operatorname{SSC}(15 \mathrm{~mm} \mathrm{NaCl}, 1.5 \mathrm{~mm} \mathrm{Na}$ citrate $), 50 \%$ formamide at $55^{\circ} \mathrm{C}$ for $2 \mathrm{hr}$. Final stringency washes were in $0.1 \times \mathrm{SSC}$ at $68^{\circ} \mathrm{C}$ for $1 \mathrm{hr}$. Sections were mounted on coated slides, dehydrated, and exposed to Kodak XAR film for $5 \mathrm{~d}$ at room temperature.

\section{Results}

Construction of directional cDNA libraries and directional tag PCR subtraction

To isolate clones of mRNAs enriched in the striatum, we followed the procedures described in the Materials and Methods section and shown schematically in Figure 1 to construct a rat striatum cDNA library directionally cloned in the T7 RNA expression vector pT7T3D18U and a rat cerebellum cDNA library directionally cloned in a different T7 RNA expression vector, pGEM11Zf(-). T7-driven cRNA transcripts from the linearized striatal library were used as template for reverse transcription in the presence of trace amounts of radioactive nucleotide triphosphate, using as primer the same NotI-oligo(dT) oligonucleotide used to construct the initial cDNA library. The labeled cDNAs were hybridized with a 20-fold excess of cRNA transcribed from the cerebellum library. After extraction and precipitation, single-stranded (unhybridized) cDNA was separated from double-stranded (hybridized) cDNA by hydroxylapatite chromatography. After the first hydroxylapatite column, $15 \%$ of the input striatum cDNA (as monitored by the radioactive tracer) eluted in the single-strand fraction. This material was subjected to a second hybridization with driver, after which $30 \%$ eluted in the double-strand position from a second hydroxylapatite column. Thus, $90 \%$ of the input target was removed by the two cycles of subtraction. The remaining target cDNA was amplified by PCR, using as primer sites the tag sequences added by the initial cloning steps, and an aliquot was cloned.

\section{Subtraction procedure increases the specific activity of striatum-enriched sequences}

To assess the effectiveness of these steps, the information content of the subtracted, amplified target cDNA was examined by dot blot analysis. Plasmid DNAs corresponding both to mRNAs expressed in striatum, but not cerebellum (RC3, CPu1, 1G5), and to mRNAs expressed equally in striatum and cerebellum (NSE, cyclophilin), as well as vector with no insert, were spotted on nylon filters and hybridized with PCR-generated cDNA probes made from the unsubtracted and subtracted cDNA target preparations. When the filter was hybridized with the unsubtracted striatum cDNA probe, strong signals were detected in the plasmids containing the cDNA inserts of cyclophilin, NSE, and $\mathrm{RC}$. The signal for CPul was weaker than these three, and the 


\begin{tabular}{|c|c|c|c|}
\hline Clone & Control cDNA library & Subtracted cDNA library & Relative frequency \\
\hline \multicolumn{4}{|l|}{ Group A } \\
\hline $\mathrm{RC} 3$ & $14 / 4,300 \quad(0.32 \%)$ & $31 / 2,860 \quad(1.08 \%)$ & 3.4-fold increase \\
\hline CPU1 & $2 / 10,910(0.018 \%)$ & $13 / 5,640 \quad(0.23 \%)$ & 12.8-fold increase \\
\hline 1G5 & $15 / 65,470(0.023 \%)$ & $25 / 14,110(0.18 \%)$ & 7.8-fold increase \\
\hline Cyclophilin & $19 / 4,300 \quad(0.44 \%)$ & $0 / 8,470$ & $>40$-fold decrease \\
\hline \multicolumn{4}{|l|}{ Group B } \\
\hline SE6C & $2 / 4,900 \quad(0.04 \%)$ & $19 / 1,560 \quad(1.22 \%)$ & 30.5-fold increase \\
\hline SE7D & $3 / 4,900 \quad(0.06 \%)$ & $13 / 1,560 \quad(0.83 \%)$ & 13.8-fold increase \\
\hline SE7E & $1 / 9,800 \quad(0.01 \%)$ & $3 / 10,900(0.027 \%)$ & 2.7-fold increase \\
\hline SE23B & $0 / 9,800 \quad(<0.01 \%)$ & $5 / 10,920(0.04 \%)$ & $>4$-fold increase \\
\hline
\end{tabular}

Group A includes cDNA clones that have been previously characterized and used to access the effectiveness of the subtraction. RC3, CPul, and 1G5 mRNAs are expressed in the striatum but not in the cerebellum, whereas cyclophilin mRNA is expressed ubiquitously in the brain. Group B includes cDNA clones that were isolated by the directional tag PCR subtraction.

signal for 1 G5 was weakest among five cDNA clones (Fig. 2A). No signal was detected with the vector. These signal intensities are reasonable as judged by the relative concentrations of the corresponding mRNAs. When the filter was hybridized with the striatum-minus-cerebellum subtracted cDNA probe, the signals for RC3, CPu 1, and 1G5 clearly increased, while the signals for NSE and cyclophilin decreased to background levels (Fig. 2B). This result clearly demonstrated that our subtraction worked well in that the specific activity of the subtracted probe increased for sequences enriched in the target but greatly decreased for sequences shared between target and driver.

The subtracted striatum cDNA target was amplified by PCR using the primers specific for the tag sequences, and cloned into the pT7T3D vector after digestion with NotI and EcoRI, which cleave within the primer sequences. The frequencies of clones corresponding to RC3, CPu1, 1G5, and cyclophilin were measured in the subtracted cDNA library and in the unsubtracted target library, which had been constructed in the same vector. Colony lifts from the unsubtracted control cDNA library and the subtracted cDNA library were hybridized with ${ }^{32} \mathrm{P}$-labeled
cDNA insert of each clone. The frequencies of RC3, CPul, and $1 \mathrm{G} 5$, which are expressed in the striatum but not in the cerebellum, significantly increased in the subtracted library compared with in the control library (Table 1, group A). On the other hand, the frequency of commonly expressed cyclophilin dramatically decreased in the subtracted cDNA library.

\section{Differential screening of the subtracted cDNA library yields striatum-specific clones}

The subtracted cDNA library and the subtracted cDNA probe were used together to isolate cDNA clones of novel "striatumspecific" mRNAs. Because the results shown in Table 1, group A, demonstrated that clones of some known "striatum-specific" mRNAs were enriched in the subtracted striatum cDNA library to relative concentrations of $>0.1 \%$, we initially analyzed only a small number of clones by differential screening. We picked and arrayed 430 clones randomly from the subtracted striatum cDNA library and hybridized replica filters with the subtracted striatum, the unsubtracted striatum, or the unsubtracted cerebellum cDNA probes. The signals in this low-density screening
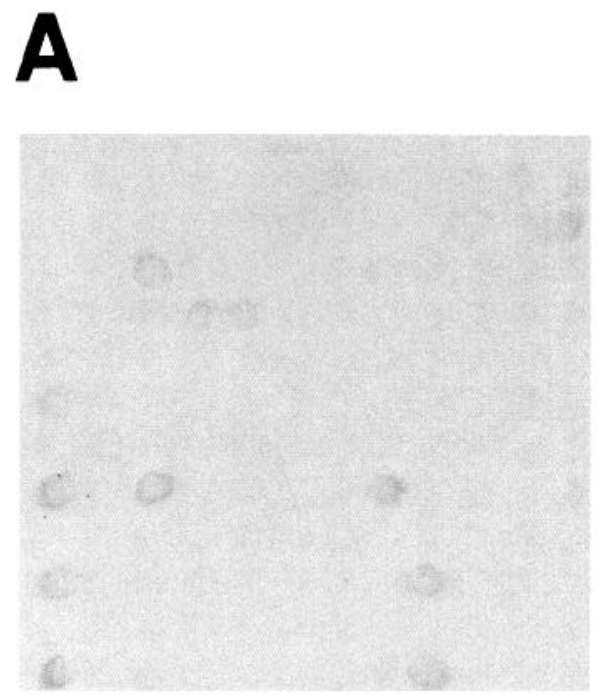
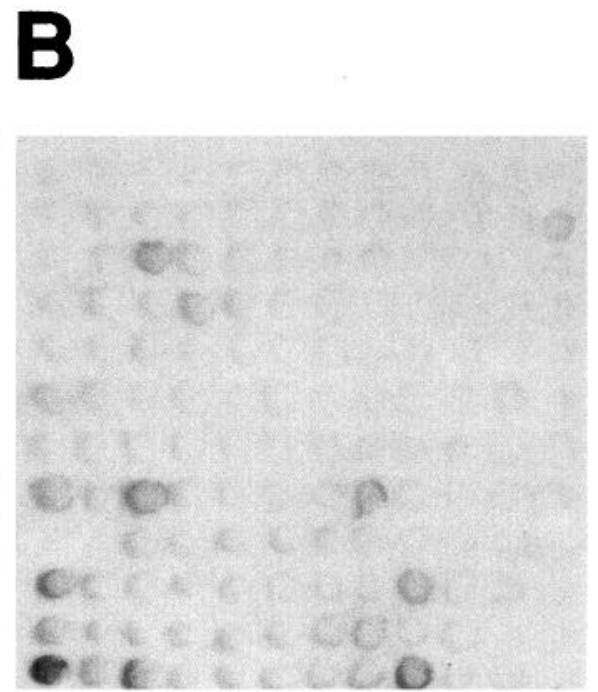
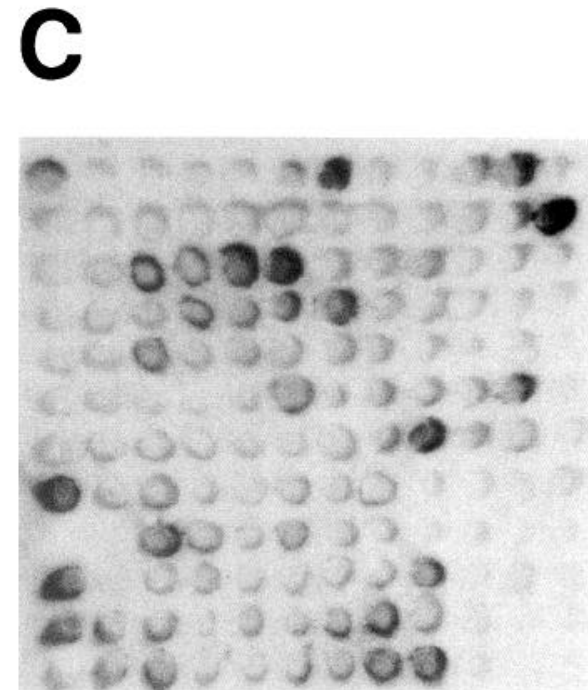

Figure 3. Differential screening of the subtracted striatum cDNA library. Clones from the striatum-minus-cerebellum subtracted library were picked and arrayed to make replica filters. Each filter was hybridized with unsubtracted cerebellum cDNA probe $(A)$, unsubtracted striatum cDNA probe $(B)$, or striatum-minus-cerebellum subtracted cDNA probe $(C)$. 
A

123

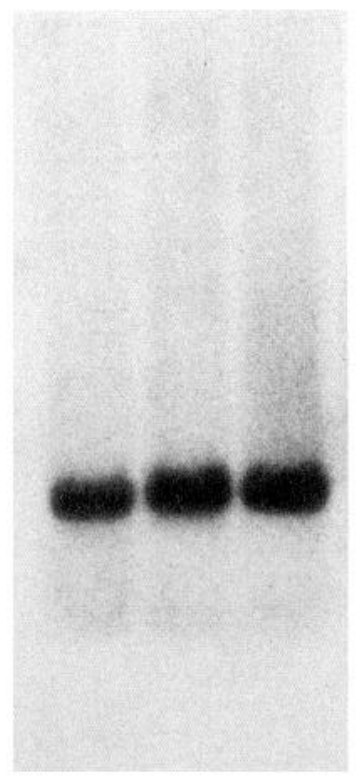

D
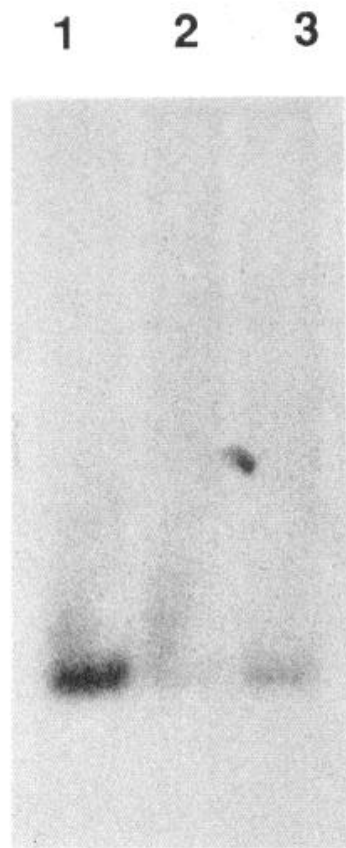

B

1

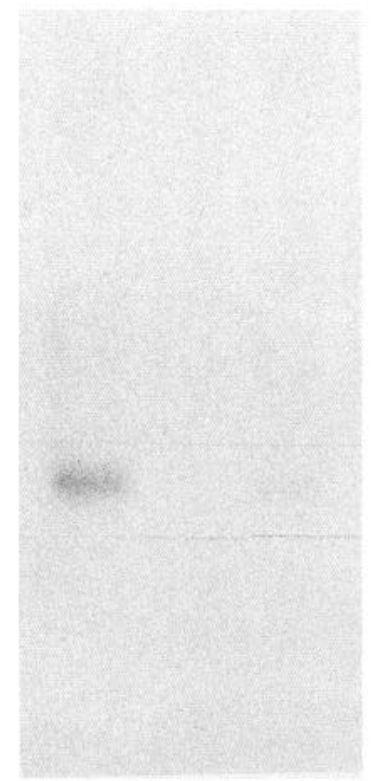

E

$\begin{array}{lll}1 & 2 & 3\end{array}$

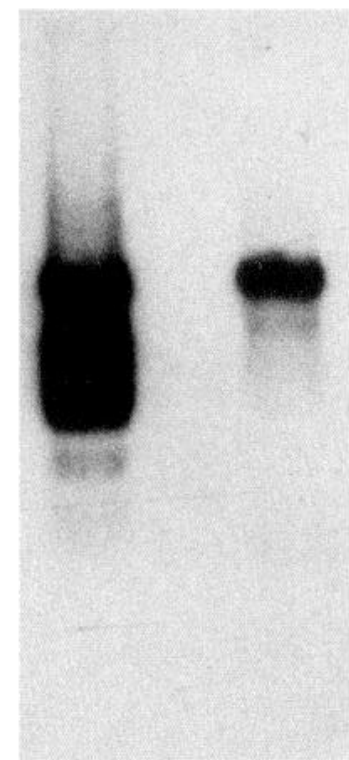

C

F

\section{3}

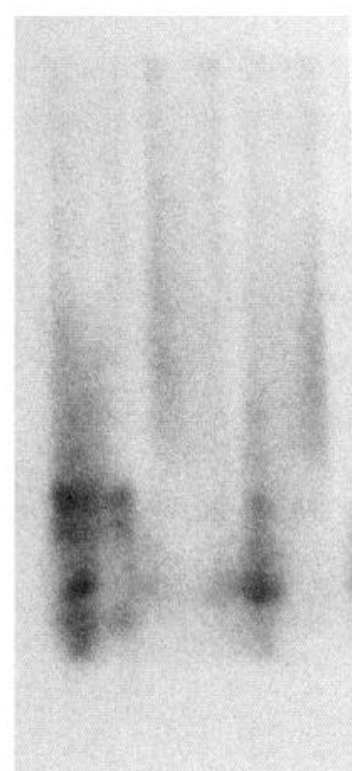

Figure 4. cDNA library-Southern blot analysis. Amplified cDNA library DNAs of striatum-pT7T3D (lane 1), cerebellum-pT7T3D (lane 2), and hypothalamus-pT7T3D (lane 3) were digested with the restriction enzyme HaeIII; the digests were separated by electrophoresis on agarose gels and transferred onto nylon filters. Each filter was hybridized with cDNA probe prepared from candidate clones selected by the differential screening of the subtracted cDNA library. 
were clear, and there was no chance of erroneous picking of the candidate clones (a difference from high-density screening of an unsubtracted cDNA library with a subtracted cDNA probe). The signal pattern of the unsubtracted striatum probe (Fig. $3 B$ ) was similar to that of the unsubtracted cerebellum cDNA probe (Fig. 3A): only a few clones showed stronger signal with the striatum probe than with the cerebellum probe. However, when the filter was hybridized with the striatum-minus-cerebellum subtracted cDNA probe (Fig. 3C), many clones showed clearly stronger signals than with the unsubtracted $c D N A$ probes. These clones were considered as candidates for clones of striatumspecific mRNAs. A few of the clones gave signals with all three probes, indicating either that subtraction had not worked for the corresponding sequences, possibly because of their higher initial concentrations in striatum compared to cerebellum, or that the high relative specific activities of the probes for these sequences are an artifact of their preferential amplification during the PCR steps used in amplification of the subtracted cDNA and in probe generation. Of the 430 clones analyzed, 40 clones (group 1) showed clearly increased signals with the subtracted striatum cDNA probe compared with the unsubtracted striatum probe, and none of these were detected with the cerebellum cDNA probe. Additionally, about 30 clones (group II) showed weak but increased signals with the subtracted striatum probe relative to the unsubtracted striatum cDNA probe, with which the signals were background level.

After excluding four RC3-homologous clones by hybridization of the filters with an RC3 probe, we selected 15 clones randomly from the 40 group I clones and nine clones from the 30 group II candidates. The cDNA inserts of several group I clones were labeled with $\alpha_{-1}^{32} \mathrm{P}-\mathrm{dCTP}$ and used as a probe for hybridization with the filters to detect overlapping clones. This cross-hybridization analysis revealed that the 15 group I clones represented eight independent families, and that seven of the nine group II clones also represented independent families. A representative of each of the 15 independent families (eight group I and seven group II candidates) was further analyzed by cDNA library-Southern blot analysis.

\section{Regional and cellular expression patterns of striatal-specific cDNAs}

As a preliminary step for elucidating the expression patterns of the mRNAs corresponding to the candidate clones, we performed cDNA library-Southern blot analysis. Although the details of the method (described in the Materials and Methods) have not yet been rigorously optimized, it has proven to be a rapid, inexpensive way to examine candidates that does not consume additional quantities of polyA + RNAs. The ${ }^{32}$ P-labeled cDNA inserts from the 15 candidate clones were used as probes for hybridization to filters displaying HaeIII digests of the striatum-pT7T3D, cerebellum-pT7T3D, and hypothalamuspT7T3D cDNA libraries. Most candidate probes showed clear differences, discriminating between the striatum and cerebellum cDNA digests (Fig. $4 B-F$ ), although some candidate clones did not show a difference (Fig. $4 A$ ). Among the 15 candidate clones, six of the eight group I clones (75\%) and three of the seven group II clones (43\%) showed clear differences in the striatum and cerebellum cDNA digests. Several clones produced a signal with the striatum cDNA digest, but with neither the cerebellum nor hypothalamus cDNA digests (Fig. $4 C, D, F$ ), suggesting an exprcssion pattern restricted to the striatum.

Subsequently, these nine definite candidate clones were an-

\begin{tabular}{llll}
\hline Table 2. & Clones studied & & \\
Clone & Figure 3 & Figure 4 & Figure 5 \\
\hline SE1A & Row 1, column 1 & $A$ & Not shown \\
SE7D & Row 4, column 7 & $B$ & $A$ \\
SE7E & Row 5, column 7 & $C$ & $D$ \\
SE6C & Row 3, column 6 & $D$ & $B$ \\
SE3E & Row 5, column 3 & $E$ & Not shown \\
SE23B & Not shown & $F$ & $C$
\end{tabular}

cDNA clones designated as "striatum enriched" (SE) were selected (except for clone SE23B) from the plate whose autoradiographs are shown in Figure 3 [positions are identified by (horizontal) row and (vertical) column] and then used for cDNA library Southern blotting (Fig. $4 A-F$ ) and Northern blotting (Fig. $5 A-D$ ).

alyzed by Northern blot assay to confirm their expression patterns and to learn their patterns in other brain regions and peripheral tissues. All nine clones selected by the differential screening and the cDNA library-Southern blot analysis showed clearly stronger signals with RNA from striatum than from cerebellum. Several RNAs showed very restricted expression pattern in the striatum of the brain, as suggested in the cDNA library-Southern blot analysis. Striatum-enriched-7D (SE7D) hybridized to an RNA expressed prominently in striatum (Fig. $5 A$ ), but detected in other brain regions at much lower concentrations, and only extremely faintly in the cerebellum and peripheral tissues. SE6C detected a target in the striatum, and only weakly in other brain areas and peripheral tissues (Fig. $5 B$ ) after long exposure. SE23B also showed a very restricted expression pattern to the striatum (Fig. 5C), similar to SE6C. SE7E was expressed most abundantly in the striatum and more weakly in the thalamus and hypothalamus (Fig. $5 D$ ). The relationships between the clones examined in the studies shown in Figures $3-5$ are indicated in Table 2.

The expression patterns of some mRNAs of newly isolated cDNA clones were examined in more detail by in situ hybridization analysis. Prominent expression of the mRNA of the SE7D clone was demonstrated in several areas of the striatum: caudate nucleus, putamen, and olfactory tubercle. Additionally, the SE7D mRNA was detected in dentate gyrus of the hippocampal formation and piriform cortex (Fig. 6A). Hybridization signals were also observed in all areas of the neocortex, and less intense signals were detected in the thalamus and hypothalamus. The SE6C mRNA was also prominently detected in caudate nucleus, putamen, and olfactory tubercle. Additionally, significant SE6C hybridization was detected in the CA1, CA2, and $\mathrm{CA} 3$ regions of the hippocampus and parietal cortex (layers II, III, IV, and VI) (Fig. 6B), which was not detected by Northern blot analysis. Therefore, the expression pattern of the SE6C mRNA is similar to that of the SE7D mRNA, as both mRNAs are prominently expressed in several areas of the striatum; however, it is distinct in the hippocampus and cortex.

\section{DNA sequence analysis of striatal-specific cDNAs}

The nucleotide sequences of the clones of striatum-enriched mRNAs were determined by dideoxy chain termination method, and the GenBank and EMBL databases were searched with their nucleotide sequences. All the candidate clones correspond to 3 '-noncoding regions, because the first-strand cDNA was synthesized with NotI-oligo(dT) primer, and most of the cDNAs were relatively short (about 300 nucleotides average length). Nevertheless, the sequences were sufficient to determine wheth- 
A
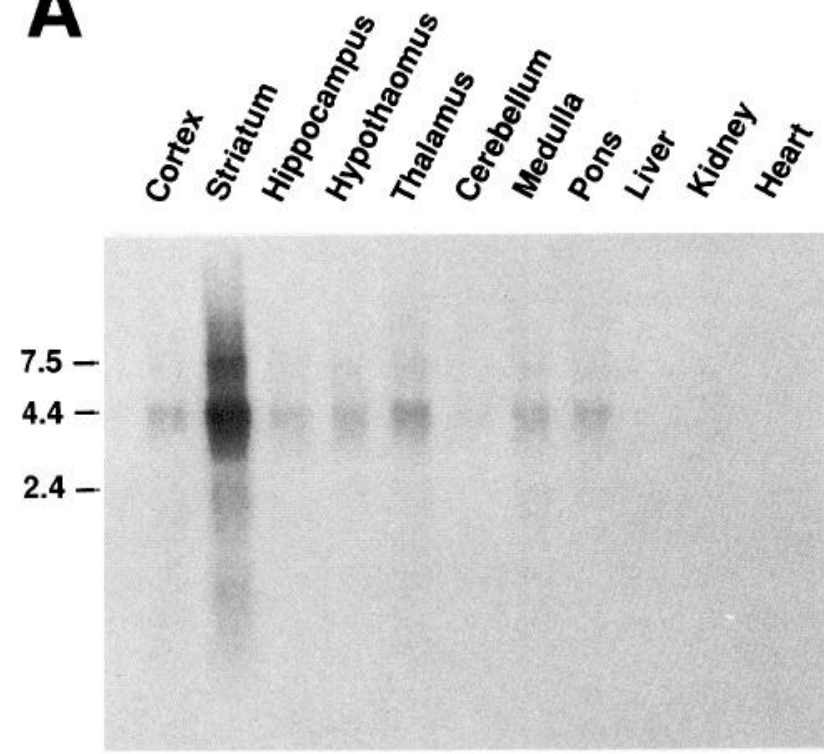

C
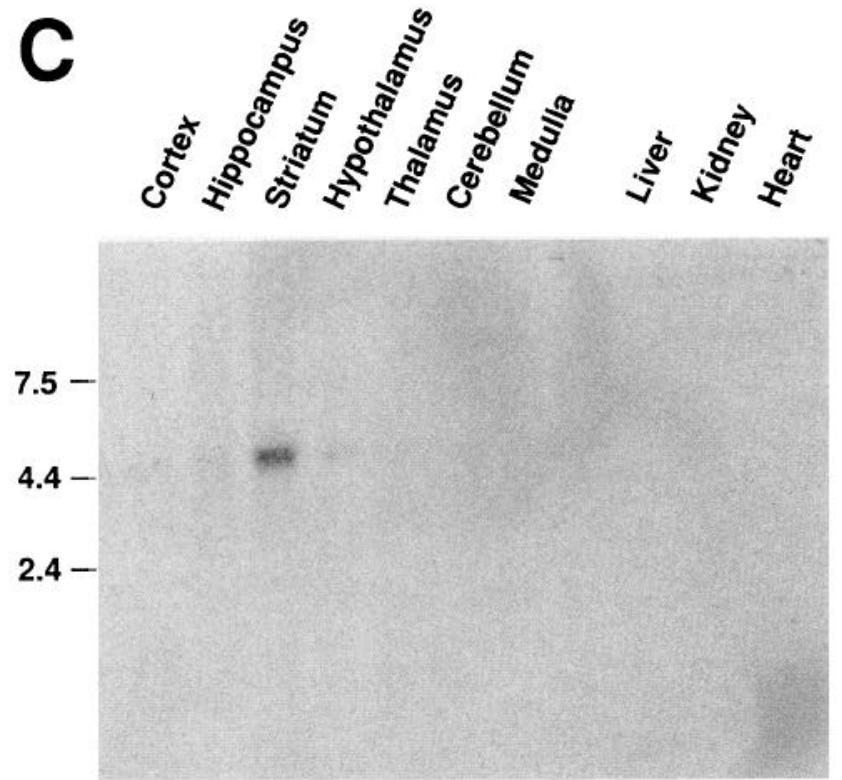

B
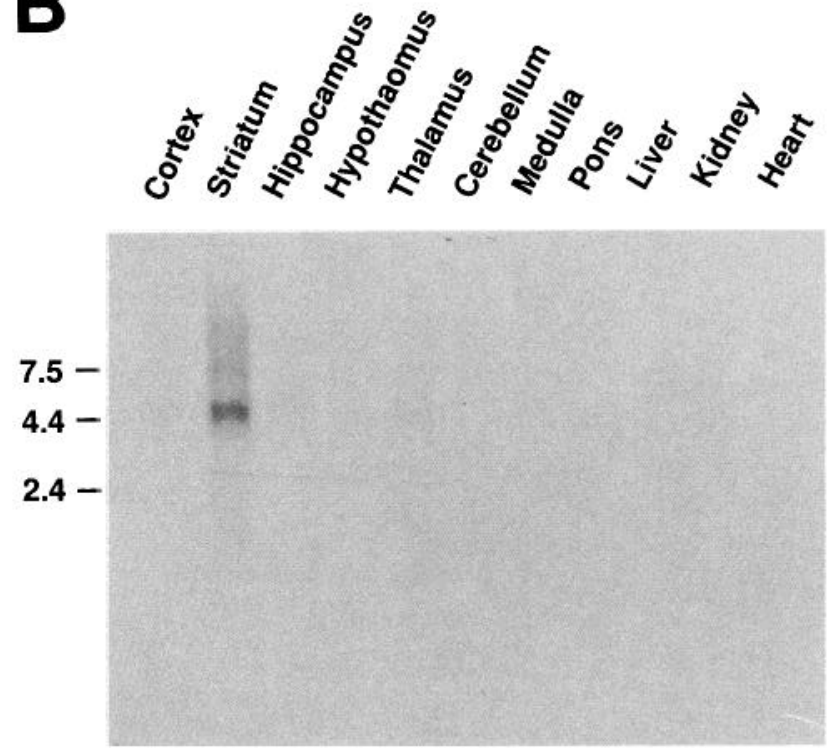

D

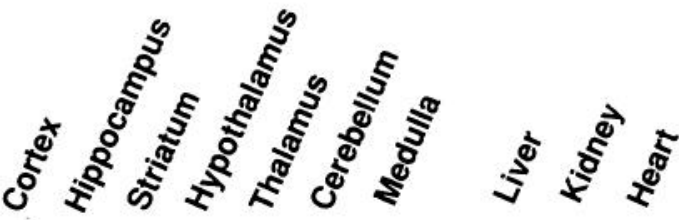

7.5

$4.4-$

$2.4-$

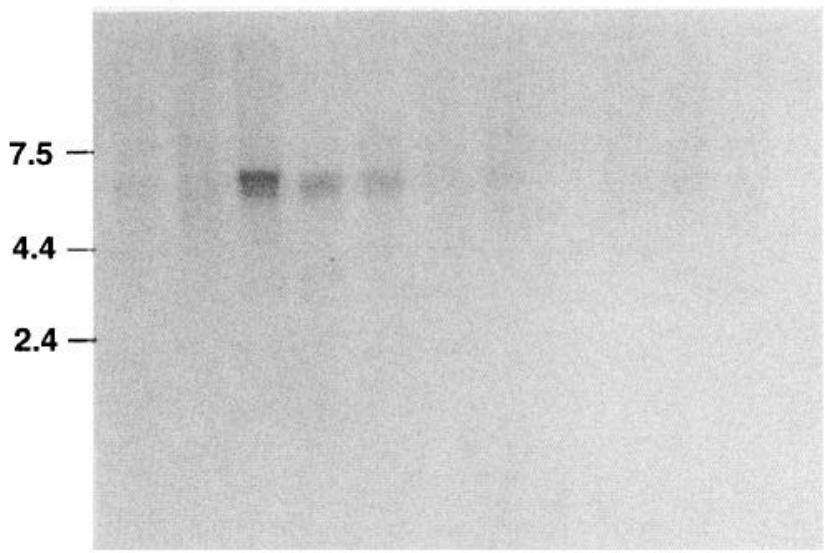

Figure 5. Northern blot analysis of striatum-enriched clones. PolyA-enriched RNA samples from rat brain regions and peripheral tissues were separated by electrophoresis and probed with SE7D $(A), \operatorname{SE6C}(B), \operatorname{SE} 23 \mathrm{~B}(C)$, and SE7E $(D)$. The mobility of size markers is indicated to the left of $A-D$.

er the clones corresponded to previously reported sequences. The sequence from the SE7D clone was identical to that of a calmodulin-dependent phosphodiesterase (Polli et al., 1992). The sequence of SE7E corresponded to a previously described transcriptional regulatory protein (Imataka et al., 1992). However, about half of the determined sequences, including those of SE6C and SE23B, showed no significant homology with any sequences in the EMBL database. The data on nucleotide sequence and Northern blot analyses of the striatum-enriched clones are summarized in Table 3 .

\section{Clones of both prevalent and rare MRNAs are detected}

Colony lifts from the unsubtracted control and the subtracted cDNA libraries were hybridized with ${ }^{32} \mathrm{P}$-labeled cDNA insert of the newly identified SE7D, SE6C, SE23B, and SE7E clones. As shown in Table 1, group B, the frequencies of SE6C and SE7D (group I) clones remarkably increased in the subtracted striatum cDNA library, compared with the control library. We roughly estimated the frequencies of SE7E and SE23B (group II) clones in the original striatum cDNA library to be $0.01 \%$ or less. Their frequencies increased significantly in the subtracted cDNA library.

\section{Discussion}

Importance of an improved subtractive cloning procedure Isolation of cDNA clones based on the distribution of their corresponding mRNAs is becoming more important for understanding the molecular mechanisms of physiological and patho- 

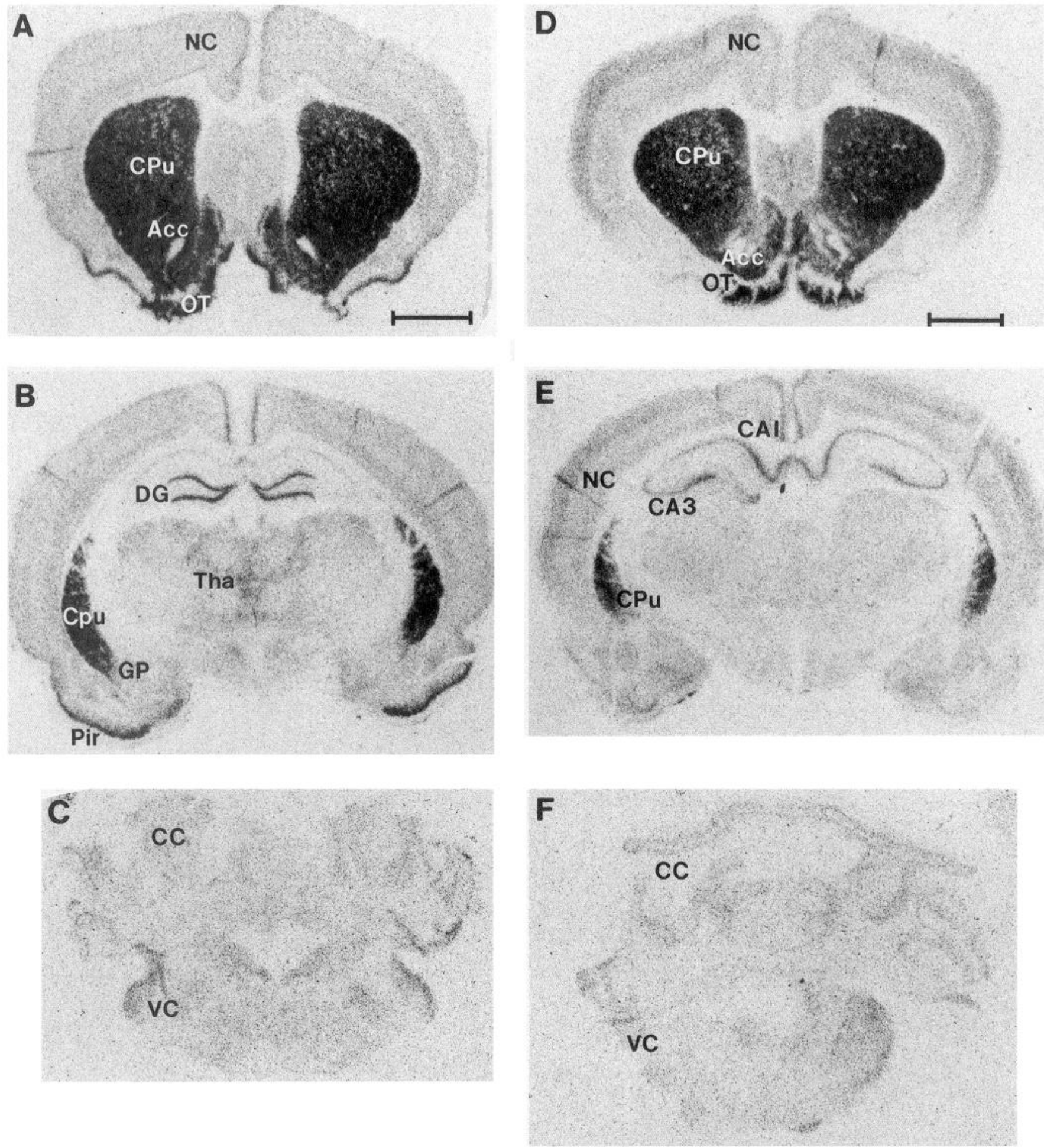

Figure 6. Expression patterns of SE7D and SE6C mRNAs analyzed by in situ hybridization. Coronal sections at three levels of rat brain were hybridized with riboprobe prepared from SE7D $(A-C)$ and SE6C clones $(D-F)$. $C P u$, caudate-putamen; $O T$, olfactory tubercle; $N C$, neocortex; $A c c$, nucleus accumbens; Pir, piriform cortex; DG, CAI, CA3, dentate gyrus, CA1 and CA3 regions of the hippocampus; GP, globus pallidus; Tha thalamus; $C C$, cerebellar cortex; $V C$, ventral cochlear nucleus. Scale bars, $2 \mathrm{~mm}$.

logical phenomena for which very limited information about the involved molecules exists. To isolate clones of differentially expressed mRNAs, subtractive cDNA cloning is the most effective method available. In many subtractive cloning approaches, a subtracted cDNA probe is prepared and used for screening of an unsubtracted cDNA library constructed from the target tissue (Miller et al., 1987; Travis et al., 1987, 1988; Yaswen et al., 1990; Jones et al., 1991). Such a screen requires the analysis of a large number of clones plated at high density. As a result the signals are not always clear and many human errors in picking are unavoidable.

On the other hand, a subtracted cDNA library improves the 


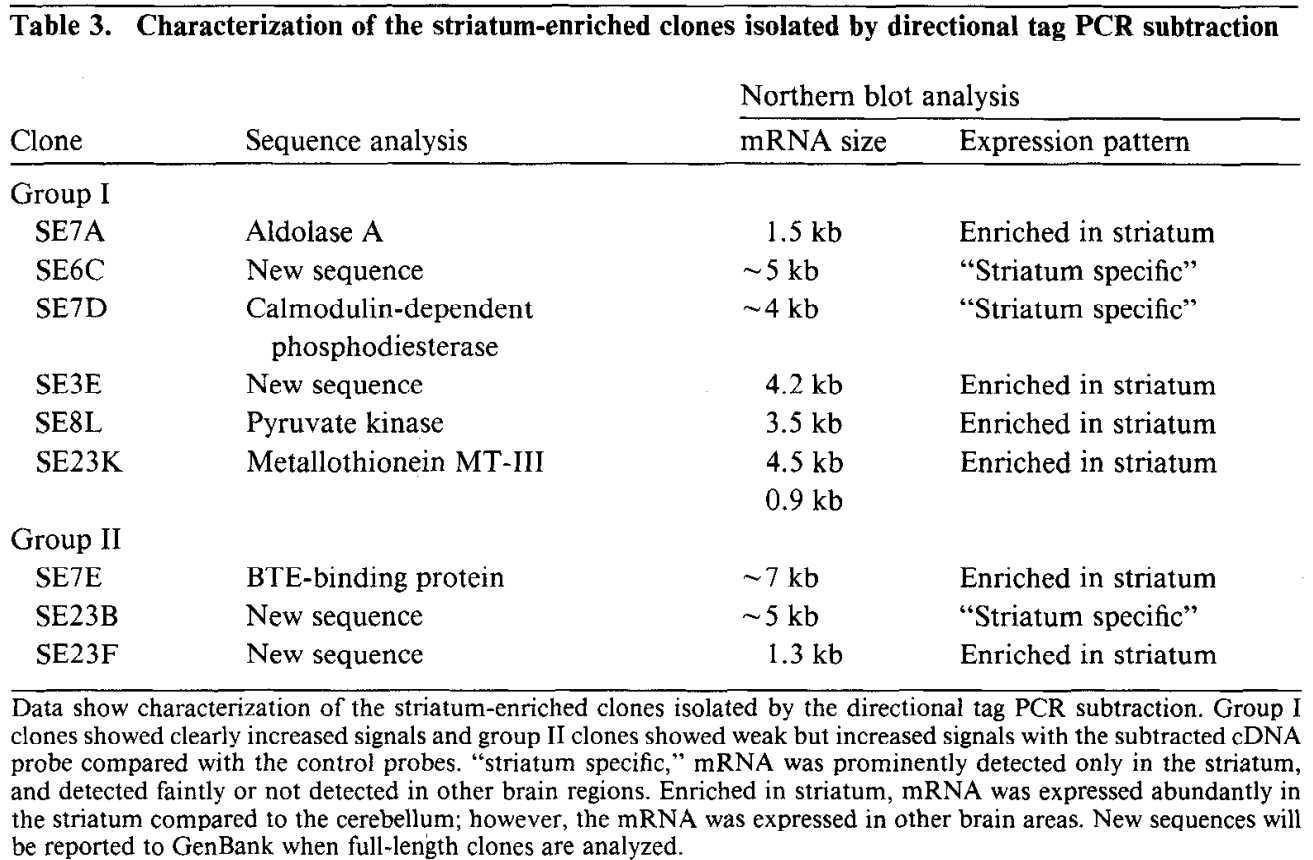

screening efficiency for isolation of clones of differentially expressed mRNAs, because these clones are enriched in the library and, therefore, a smaller number need to be analyzed, making low-density screening feasible. Construction of subtracted cDNA libraries has been difficult, although several procedures have been reported. These methods can be classified into the following three categories. The first is the so-called classical method in which subtracted cDNA fragments are converted to doublestranded DNA, ligated to linkers, and then cloned (Hedrick et al., 1984; Rhyner et al., 1986, 1990; Zopf et al., 1987; Palazzolo et al., 1989). This method is technically difficult because of the low mass of cDNA target after the subtractive hybridization. Second, in a more recent procedure, single-stranded phagemid DNA is used as target and is transfected directly after the removal of the hybridized target (Duguid et al., 1988, 1989; Nordquist et al., 1988; Rubenstein et al., 1990; Swaroop et al., 1991). In these methods, the construction of the subtracted cDNA library is relatively easy. However, because of the low transfection efficiency of single-stranded phagemid DNA, only a small number of transformants are usually obtained. Another disadvantage of these methods is that, because there is no labeling of the target, quantitation of the effectiveness of the subtraction is difficult. The third category includes the PCR-based methods, in which subtracted cDNA fragments are amplified by PCR and then ligated into a vector. This approach avoids the limitations of the former two categories. In previously reported PCR-based methods, the primer-binding site is either ligated to a subtracted cDNA target (Timblin et al., 1990) or added by terminal transferase in the form of a polydeoxyguanidine tail (Zaraisky et al., 1992). Again, linker ligation to the subtracted cDNA poses a technical challenge because of the very low mass of the target after subtraction. On the other hand, anchor PCR using the dG tail for priming has the possibility of nonspecific interaction during hybridization and nonspecific amplification during PCR due to GC-rich sequences in the target. These limitations suggested a need for more dependable procedures.

\section{Characteristics of the directional tag $P C R$ subtraction}

We developed an alternative procedure for constructing a subtracted cDNA library. Some of its important features are also present in the method described briefly by Klar et al. (1992). Our method uses a specially designed cDNA target and an RNA driver prepared in vitro from the directional cDNA libraries, avoiding the disadvantages of the previous PCR-based procedures. Linker ligation is not necessary after the subtraction because the target cDNA already contains tag sequences for the PCR and the cDNA target does not have GC-rich sequences such as those in a poly(dG) tail. The procedure has another important feature: there are no sequences in common between the vector-derived portions of the target and driver transcripts. Furthermore, because the driver is RNA, it is easily eliminated after the hydroxylapatite column and thus is not artifactually included after the subtraction. Using cRNA as driver prohibits the use of PERT, by which high $\mathrm{C}_{0} \mathrm{t}$ values can be obtained, but that did not prove disadvantageous in our study. Because the product of the procedure is PCR amplifiable, it is replenishable and can be used to verify the extent of subtraction, and could be recycled and subtracted with a driver prepared from yet another tissue source so as to add a second dimension of selectivity. The amount of radioactive isotope utilized is drastically less than with procedures in which the probe is labeled before subtraction.

Another advantage of the method is that both the target and the driver are prepared from directional cDNA libraries, thus only $1-2 \mu \mathrm{g}$ of polyA + RNA are required from the target and driver tissues. This characteristic may be important when large amounts of polyA ${ }^{+}$RNA are hard to prepare from target or the driver tissues and opens possible applications to a number of biological or pathological problems. The cDNA library-Southern blot analysis, discussed below, is also useful for reducing the tissue requirement, as clones of differentially expressed mRNAs can be identified without consumption of additional polyA ${ }^{+}$ 
RNA once libraries have been prepared. We would like to point out the possibility of further refinements of these procedures: when combined with the PCR-based directional cDNA library construction and in situ hybridization analysis for the final confirmation of the distribution, an even greater reduction of the tissue requirement could be achieved, allowing studies when exceptionally small quantities of tissues are available (e.g., human biopsy materials, animal tissues of very early developmental stages, tissue punches, primary cultured cells, or even single cells). Despite its many advantages, users of the method should be cognizant of a few potential pitfalls. First, the method relies upon cDNA libraries that might not be exactly representative of initial mRNA concentrations. Second, PCR amplifications may not be uniform across the cDNA populations, leading to the isolation of false positive clones that are not actually enriched in the target tissue but are only enriched by the technique. Our false positive rate was quite low, as discussed below. Nevertheless, it is imperative that each product clone be considered as a candidate until the distribution of its corresponding mRNA is examined in the starting tissues. Limitations of the methodology due to the above considerations are minimized by the efficient screening procedures in the subsequent steps.

This directional tag PCR subtraction procedure was quickly adapted separately by two of the authors for use with different targets, and comparable results to those reported above were obtained; thus, the method is reproducible and should be portable because all of the reagents are commercially available.

\section{Selection procedure for candidate clones}

In this procedure, both subtracted probes and subtracted libraries can be prepared by PCR from the subtracted cDNA target. By screening a subtracted striatum cDNA library with a subtracted striatum cDNA probe, we efficiently isolated differentially expressed cDNA clones. We obtained 40 strong (group I) and 30 weak (group II) candidates from 430 clones from the subtracted cDNA library. Subsequent analysis revealed that $75 \%$ of the group I and $>40 \%$ of group II clones showed clearly stronger signals in striatum than cerebellum. The high ratio of bona fide clones to false positives was greatly facilitated by the clear signals observed in the low-density differential screening step in which there is almost no possibility of human error in colony picking.

In our procedure, we used CDNA library-Southern blot analysis after the differential screening of the subtracted cDNA library. This step, which has not yct becn subjected to rigorous optimization, has several advantages. More definite candidates can he selected before Northern blot or in situ hybridization analysis, which are generally more laborious tasks. The filters for this approach can be prepared without additional polyA ${ }^{+}$ RNA, and the probe can be prepared by PCR using miniprep plasmid DNAs as a template and only small quantities of radioactive nucleotides. The candidates can be screened at this stage for expression in other tissues. In our study, we examined whether the candidates were expressed in the hypothalamus, allowing us to identify clones of "striatum-specific" mRNAs, and our results correlated well to those later obtained by Northern blot analysis.

\section{Unexpected number of striatum-enriched $M R N A s$}

A precise estimate of the number of mRNAs that are "striatum specific" is not possible because we selected subsets of clones at a few stages of the analysis; however, rough calculations can be made. We initially screened 430 clones from a library made from amplified cDNA from which $90 \%$ of the mass had been removed by directional tag PCR subtraction, and detected 70 clones. Study of 24 of these showed they correspond to 15 families, of which nine hybridized to mRNAs clearly enriched in striatum over cerebellum. Three of these (SE7D, SE6C, and SE23B) mRNAs were expressed prominently in the striatum, and were detected only very faintly or not at all in other brain regions and peripheral tissues. These data suggest that approximately $1 \%$ of the polyA ${ }^{+}$RNA mass corresponds to striatal species greatly reduced or absent from cerebellum, of which about a third arc "striatum-specific." It has previously been calculated (Milner and Sutcliffe, 1983) that roughly 30,000 mRNAs are expressed within the brain. The present study suggests that at least 300 have enriched expression within striatum, of which perhaps 100 may be highly restricted to that structure. Because species expressed at low concentrations constitute the largest portion of the molecular complexity, these numbers may be underestimates.

Nucleotide sequence analyses revealed that one of the newly isolated "striatum-specific" clones (SE7D) encodes a calmodulin-dependent phosphodiesterase (Polli et al., 1992), but two of the sequences (SE6C and SE23B) are novel. So far, only a few mRNAs have been reported to be expressed in the striatum in a specific manner, including those encoding adenylyl cyclase type V (Glatt and Snyder, 1993), an $\alpha$ subunit of the GTPbinding protein named $\mathrm{G}_{\text {or }}$ (Herve et al., 1993); CPul, which encodes the G-protein subunit $\gamma 7$ (Watson et al., 1992, unpublished observations); the striatal-enriched phosphatase STEP (Lombroso et al., 1993); and the $D_{1}$ dopamine receptor (Fremeau et al., 1991; Moine et al., 1991).

The mRNA corresponding to the SE7D clone, which encodes a calmodulin-dependent phosphodiesterase, was expressed in the striatum, dentate gyrus of the hippocampal formation, piriform cortex, and neocortex, which was not reported previously. That for SE6C was expressed in CA1, CA2, and CA3 regions of the hippocampus and parietal cortex, in addition to in the striatum. Thus, despite strong similarities in expression, the differences observed suggest differences in the physiological functions to which the two relate. Our findings suggest that the striatum contains a large number of unique molecules, many of which appear to be related to signal transduction. Characterization of these will undoubtedly be important for understanding the striatum, which is involved in the control of movement and posture, is implicated in aspects of complex behavioral functions, and is a target for selective neuronal loss in some neurodegenerative disorders such as Huntington's disease.

\section{Possible mechanisms of striatum-specific gene expression}

The SE7E mRNA encodes a transcriptional regulatory protein reported recently (Imataka et al., 1992) to bind to a GC box sequence and have a function similar to, but distinct from, $\mathrm{Sp}$, the prototype GC box-binding factor. This mRNA is expressed most abundantly in the striatum, weakly in the thalamus and hypothalamus, and faintly in other brain regions. This distribution suggests that SE7E may be involved in specific gene expression within striatum, perhaps contributing to the regulation of the cell-type-specific expression of some of the mRNAs detected here (SE7D, SE6C, SE23B) or previously (adenylyl cyclase type $\mathrm{V}, \mathrm{G}_{\mathrm{oll}}, \mathrm{D}_{1}$ dopamine receptor). 


\section{References}

Britten RJ, Graham DE, Neufeld BR (1974) Analysis of repeating DNA sequences by reassociation. Methods Enzymol 29:363-418.

Brutlag DL, Dautricourt JP, Maulik S, Rclph J (1990) Improved sensitivity of biological sequence database searches. Comput Appl Biosci $6: 237-245$

Chomczynski P, Sacchi N (1987) Single-step methods of RNA isolation by acid guanidinium thiocyanate-phenol-chloroform extraction. Anal Biochem 162:156-159.

Danielson PE, Forss-Petter S, Brow MA, Calavetta L, Douglass J, Milner R, Sutcliffe JG (1988) P1B15: a cDNA clone of the rat mRNA encoding cyclophilin. DNA 7:261-267.

Dower WJ, Miller JF, Ragsdale CW (1988) High efficiency transformation of $E$. coli by high voltage electroporation. Nucleic Acids Res 16:6127-6145.

Duguid JR, Rohwer R, Seed B (1988) Isolation of cDNAs of scrapiemodulated RNAs by subtractive hybridization of a cDNA library. Proc Natl Acad Sci USA 85:5738-5742.

Duguid JR, Bohmont CW, Liu N, Tourtellotte WW (1989) Changes in brain gene expression shared by scrapie and Alzheimer disease. Proc Natl Acad Sci USA 86:7260-7264.

Dworkin MB, Dawid IB (1980) Construction of a cloned library of expressed embryonic gene sequences from Xenopus laevis. Dev Biol 76:435-448.

Erlander MG, Lovenberg TW, Baron BM, Lecea LD, Danielson PE Racke M, Slone AL, Siegel BW. Foye PE, Cannon K, Burns JE, Sutcliffe JG (1993) Two members of a distinct subfamily of 5-hydroxytryptamine receptors differentially expressed in rat brain. Proc Natl Acad Sci USA 90:3452-3456.

Forss-Petter S, Danielson P, Sutcliffe JG (1986) Neuron-specific enolase: complete structure of rat mRNA, multiple transcriptional start sites, and evidence suggesting post-transcriptional control. J Neurosci Res 16:141-156.

Fremeau RT Jr, Duncan GE, Fornaretto MG, Dearry A, Gingrich JA Breese GR. Caron MG (1991) Localization of $D_{1}$ dopamine receptor mRNA in brain supports a role in cognitive, affective, and neuroendocrine aspects of dopaminergic neurotransmission. Proc Natl Acad Sci USA 88:3772-3776.

Gall CM, Isackson PM (1989) Limbic seizures increase neuronal production of messenger RNA for nerve growth factor. Science 245:758761

Glatt CE, Snyder SH (1993) Cloning and expression of an adenylyl cyclase localized to the corpus striatum. Nature 361:536-538.

Godbout M, Erlander MG, Hasel KW, Danielson PE, Wong KK, Battenberg ELF, Bloom FE, Sutcliffe JG (1994) A calmodulin-binding, vesicle-associated, protein kinase-like protein enriched in forebrain neurites. J Neurosci 14:1-13.

Hedrick SH, Cohen DI, Nielsen EA, Davis MM (1984) Isolation of cDNA clones encoding $T$ cell-specific membrane-associated protein. Nature 308:149-153.

Herve D, Levi-Strauss M, Marey-Semper I, Verney C, Tassin JP, Glowinski J, Girault JA (1993) $G_{o l}$ and $G_{s}$ in rat basal ganglia: possible involvement of $G_{\text {in }}$ in the coupling of dopamine $D_{\text {, receptor with }}$ adenylyl cyclase. J Neurosci 13:2237-2248.

Imataka H, Sogawa K, Yasumoto K, Kikuchi Y, Sasano K, Kobayashi A, Hayami M, Fujii-Kuriyama Y (1992) Two regulatory proteins that bind to the basic transcription element (BTE), a GC box sequence in the promoter region of the rat P-4501 Al gene. EMBO J 11:36633671 .

Jones KW, Shaero MII, Chevrette M, Fournier REK (1991) Subtractive hybridization cloning of a tissue-specific extinguisher: TSE 1 encodes a regulatory subunit of protein kinase A. Cell 66:861-872.

Klar A, Baldassare M, Jessell TM (1992) F-spondin: a gene expressed at high level in the floor plate encodes a secreted protein that promotes neuronal cell adhesion and neurite extension. Cell 69:95-1 10.

Lombroso PL, Naegele JR, Sharma E, Lerner M (1993) A protein tyrosine phosphatase expressed within dopaminoceptive neurons of the basal ganglia and related structure. J Neurosci 13:3064-3074.

Miller FD, Naus CCG, Higgins GA, Bloom FE, Milner RJ (1987)
Developmentally regulated rat brain mRNAs: molecular and anatomical characterization. J Neurosci 7:2433-2444.

Milner R, Sutcliffe JG (1983) Gene expression in rat brain. Nucleic Acids Res 1 1:5497-5520.

Moine CL, Normand E, Bloch B (1991) Phenotypical characterization

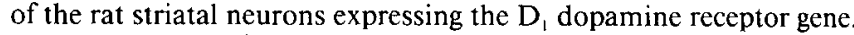
Proc Natl Acad Sci USA 88:4205-4209.

Nordquist DT, Kozak CA, Orr H (1988) cDNA cloning and characterization of three genes uniquely expressed in cerebellum by Purkinje neurons. J Neurosci 8:4780-4789.

Palazzolo MJ, Hyde DR, VijayRaghavan K, Mecklenburg K, Benzer S, Meyerowitz E (1989) Use of a new strategy to isolate and characterize 436 Drosophila cDNA clones corresponding to RNAs detected in adult heads but not in early embryos. Neuron 3:527-539.

Polli JW, Kincaid RL (1992) Molecular cloning of DNA encoding a calmodulin-dependent phosphodiesterase enriched in striatum. Proc Natl Acad Sci USA 89:11079-11083.

Rhyner TA, Biguet NF, Barrard S, Borbely AA, Mallet J (1986) An effective approach for the subtractive isolation of specific transcripts from complex brain mRNA populations. J Neurosci Res 16:167-181.

Rhyner TA, Lecain E, Pessac B (1990) Isolation of cDNAs from a mouse astroglial cell line by a subtracted cDNA library. J Neurosci Res 27:144-152.

Rubenstein JLR, Elizabeth A, Brice J, Ciaranello RD, Denney D, Porteus MH, Usdin TB (1990) Subtractive hybridization system using single-stranded phagemids with directional inserts. Nucleic Acids Res 18:4833-4842.

Sambrook J, Fritsch EF, Maniatis T (1989) Molecular cloning: a laboratory manual. New York: Cold Spring Harbor Laboratory.

Swaroop A, Xu J, Agarwal N, Weissman SM (1991) A simple and efficient cDNA library subtraction procedure: isolation of human retina-specific cDNA clones. Nucleic Acids Res 19:1954.

Timblin C, Battey J, Kuehl WK (1990) Application for PCR technology to subtractive cDNA cloning: identification of genes expressed specifically in murine plasmacytoma cells. Nucleic Acids Res 18 1587-1593.

Travis GH, Sutcliffe JG (1988) Phenol emulsion-enhanced DNA-driven subtractive cDNA cloning: isolation of low-abundance monkey cortex-specific mRNAs. Proc Natl Acad Sci USA 85:1696-1700

Travis GH, Naus CG, Morrison JH, Bloom FE, Sutcliffe JG (1987) Subtractive cloning of complementary DNAs and analysis of messenger RNAs with regional heterogeneous distribution in primate cortex. Neuropharmacology 26:845-854.

Travis GH, Brennan MB, Danielson PE, Kozak CA, Sutcliffe JG (1989a) Identification of a photoreceptor-specific mRNA encoded by the gene responsible for retinal degeneration slow (rds). Nature 338:70-73.

Travis GH, Milner RJ, Sutcliffe JG (1989b) Preparation and use of subtractive cDNA hybridization probes for cDNA cloning. Neuromethods 16:49-78.

Watson JB, Battenberg EF, Wong KK, Bloom FE, Sutcliffe JG (1990) Subtractive cDNA cloning of RC3, a rodent cortex-enriched mRNA encoding a novel 78 residue protein. J Neurosci Res 26:397-408.

Watson JB, Coulter PM II, Sutcliffe JG (1992) Identification of genes enriched in expression in mammalian neostriatum and neocortex. Brain Dysfunct 5:94-105.

Yaswen P, Smoll A, Peehl DM, Trask DK, Sager R, Atampfer MR (1990) Down-regulation of a calmodulin-related gene during transformation of human mammary epithelial cells. Proc Natl Acad Sci USA 87:7360-7364.

Zaraisky AG, Lukyanov SA, Vasiliew OL, Smirnov YV, Belyavsky AV, Kazanskaya OV (1992) A novel homeobox gene expressed in the anterior neuronal plate of the Xenopus embryo. Dev Biol 152:373382.

Zopf D, Hermans-Borgmeyer I, Gundelfinger ED, Betz H (1987) Identification of gene products expressed in the developing chick visual system: characterization of a middle-molecular-weight neurofilament cDNA. Genes Dev 1:699-708. 